\title{
Effectiveness of Dance in Enhancing Preschooler's Flexibility
}

\author{
Syed Kamaruzaman Syed Ali, Jenny Wong Eng Yee, \\ Rahmat Sukor Ab Samad, Megat Ahmad Kamaluddin Megat Ahmad \\ University of Malaya, Kuala Lumpur, Malaysia \\ Habib Mat Som, Norkhalid Salimin \\ Sultan Idris Education University, Tanjong Malim, Malaysia
}

\begin{abstract}
The purpose of this study is to examine the effectiveness of a 45-minute weekly dance session in enhancing the flexibility of six years old boys from a kindergarten in the state of Penang, Malaysia. A total number of 30 boys were involved in this study. Fifteen subjects $(N=15)$ were chosen as the control group, while the other 15 subjects $(N=15)$ as the experimental group. The dance sessions were carried out once a week for eight weeks continuously. The paired $t$-test analysis showed that there was no significance difference $(p>0.05)$ between pre- and post-test within the control group. However, there was a significance difference $(p<0.05)$ between the pre- and post-test within the experimental group. The independent $t$-test on both groups indicated no significance difference $(p<0.05)$ between the mean scores of the control and experimental groups. Although there was no significant difference between the control and experimental groups, the mean score obtained $(M=3.40)$ implied that there were developments on the level of flexibility among the boys, after they have been undergoing the dance activities for eight weeks.
\end{abstract}

Keywords: dance, flexibility, pre-schoolers

\section{Introduction}

The level of physical fitness among the school-aged children in Malaysia is in a decreasing rate (Salamudin \& Harun, 2013; Rengasamy, 1998). American College of Sports Medicine [ACSM] (1998a) stated that an individual can easily do his or her daily activities, if they are healthy physically. In other words, the individual has enough energy to do his or her tasks.

The decreasing rate of the physical fitness of children may due to video and computer-based games. Given the pervasiveness of their influence, it is likely that these games may affect the health and well-being of children (Dorman, 1997). Children spend most of their time sitting down in front of the games and move less. They slowly become not interested in other activities. As reported by Müller, Khoo, and Lambert (2013), physical activity prevalence studies have found low physical activity rates among Asian school-age children and adolescents.

Syed Kamaruzaman Syed Ali, Ph.D., University of Malaya, Kuala Lumpur, Malaysia.

Jenny Wong Eng Yee, B.Ed., University of Malaya, Kuala Lumpur, Malaysia.

Rahmat Sukor Ab Samad, M.Ed., University of Malaya, Kuala Lumpur, Malaysia.

Megat Ahmad Kamaluddin Megat Ahmad, Ph.D., University of Malaya, Kuala Lumpur, Malaysia.

Habib Mat Som, Ph.D., Sultan Idris Education University, Tanjong Malim, Malaysia.

Norkhalid Salimin, Ph.D., Sultan Idris Education University, Tanjong Malim, Malaysia.

Correspondence concerning this article should be addressed to Syed Kamaruzaman Syed Ali, Faculty of Education, University of Malaya, 50603 Kuala Lumpur, Malaysia. E-mail: syedkamaruzaman@gmail.com. 
In schools, there are studies which find that physical activities level of a student who left school is decreasing and they become laid back. Therefore, the awareness of physical fitness has to be implemented since early years of childhood. Kindergarten may insert more music and movement sessions in daily lessons, organize outdoor sports, or encourage children to dance.

Dancing is a highly physical activity (Lake, 2013). Through dancing or other physical activities, children will build muscle strength and increase flexibility. They will develop a sense of balance and improve agility and coordination (Strickland, 2006). In other way, it helps children to feel relaxed and relieve their stress. It is also a great way to help a child to develop a positive lifelong attitude about staying active and healthy (Strickland, 2006). According to Pro Dance Centre, regular dance practice can increase a child's flexibility, range of motion, physical strength, stamina, muscle tone, correct poor posture, increase balance and coordination, and improve overall cardiovascular health (Lake, 2013).

Many have stated that increasing flexibility is one of the benefits of dancing. Flexibility is included as one of the component of physical fitness. One of the most important purposes to increase flexibility is to reduce the risk of injury. The more flexible a child is, the lesser risk of injury he will get. Nowadays, children are facing problems with their physical flexibility. The problem is either too tight or too lose.

The American Council on Exercise reported that children begin to sit often at a desk at the age of six years old. In this regular position, children's hamstrings are becoming tight and this position should be shortened. When these children grew up, they spend their time with TV and computer games. Spending too much time sitting or hunch in front of these gadgets leads to problems, such as tight legs, neck, back, and shoulders. The Nationwide Children's Hospital website adds that muscles tend to be tight in the pre-teen and early teen years, when children experience short periods of rapid growth (Fisk, 2013). Poor flexibility will become a problem during this stage of physical development, because the muscles have not adjusted well to the fast-growing bones.

Poor flexibility in the hamstring and lower back is related to problems in executing and sustaining motor activities in daily life (Bergstrom et al., 1985; Myers \& Huddy, 1985) and in some more serious cases, it will lead to chronic musculoskeletal injuries and back problems, postural deviations, gait limitation, and risk of falling, according to ACSM (1998a), Skinner and Oja (1994), and Witvrouw, Lysens, Bellemans, Cambier, and Vanderstraeten (2000).

Another problem that occurs is hypermobile or double-jointed. It refers to the children who are unusually flexible. Children with hypermobile have loose joints and their limbs are moving beyond the limit, for instant, a child can bend his fingers more than what normal people can do. Some hypermobility children's muscles will grow stronger and tighter which normalise the joint mobility however, in some cases according to Cleveland Clinic website, the symptoms will continue into adulthood.

Therefore, children must be encouraged to involve more in physical activities. Kindergarten will be one of the best places to implement this awareness, because most of their time is spent in kindergarten while their parents are working.

An opportunity to participate in regular movement activities shall be given to pre-schoolers. Unfortunately, classroom teachers receive a little training in movement and members of the dance community receive little training in child development (Sell, 2004). Most teachers do not treat music and movement as an important session in daily lesson. They maybe just sing a few songs or memorise some nursery rhymes with the children without doing much movements. The common way to carry out music and movement session is either sitting in a circle or standing in lines and imitate teacher or music videos. 
Music and movement in daily lesson can include nursery rhymes, singing, doing movements, playing music instruments, and also dancing. From the name itself, "music" and "movement" shall be carried out together and not to be separated. However, some teachers may emphasize too much on language and literacy development (singing and nursery rhymes) and neglect the physical development that can be improved through movements (dancing and playing musical instruments).

Hence, the purpose of this study is to examine to what extent the effectiveness of 45-minute dance session per week within eight weeks in enhancing pre-schoolers' flexibility from one of the kindergartens will be in Penang. Hopefully, the finding of this study creates awareness to the educators and the importance of dance and flexibility to parents and children.

\section{Flexibility}

Flexibility is a health-related component of physical fitness that relates to the range of motion available at a joint. The interest in the study of flexibility increased in early 1990s, due to the increased number of orthopaedic resulting from World War I and the epidemic of polio (Corbin \& Noble, 1980). Researchers have improved the techniques on measuring flexibility and studies in this area become an important concern regarding health and fitness.

Corbin and Noble (1980) mentioned that American children were not able to perform simple muscular strength and flexibility tasks. In spite of the interest created by Kraus-Weber test results of the 1950s, flexibility items were not included in the American Alliance for Health, Physical Education, Recreation, and Dance [AAHPERD] (1980) test batteries which were endorsed by the President's Council and which were used as a basis for national youth fitness awards (Corbin \& Noble, 1980). However, it was finally been included in the test batteries after few years. Flexibility is now recognised by most physical educators and exercise experts as an important component of health related fitness (Corbin \& Noble, 1980).

Kraus and colleagues' early work has helped to recognise the importance of flexibility to such good health practices as proper care of the back and good posture (Corbin \& Noble, 1980). Moreover, De Vries' work which pointed out the value of passive stretch in developing flexibility and reducing muscle soreness (Corbin \& Noble, 1980).

Among those particularly extolling the virtue of flexibility exercises are physical educators, coaches, referees, athletic trainers, and medical doctors. Now, professionals as well as athletes endorsed in regular flexibility program which was thought to be unimportant few years back (Corbin \& Noble, 1980). Authors in the magazines of the movement have also pointed out the values of stretching exercises and warming-ups (Corbin \& Noble, 1980).

The ability of an individual to move smoothly depends on his flexibility, an attribute that enhances both safety and optimal physical activities (Odunaiya, Hamzat, \& Ajayi, 2005). The hamstrings are example of muscle groups that have a tendency to shorten (Turner, Gossman, Nicholson, \& Lemons, 1988). Flexibility can be enhanced by simple, non-surgical procedures like stretching the shortened muscles. Stretching techniques such as cyclic stretching (Turner et al., 1988), isometric exercise (Medeiros, Smidt, Burmeiser, \& Soderberg, 1977), proprioceptive neuromuscular facilitation protocol, and static stretching (Worrell, Smith, \& Winegardner, 1994), have been used to enhance muscular flexibility. One of the factors that may likely affect the outcome of the non-surgical intervention is the duration for which any of the techniques is applied (Odunaiya et al., 2005). 
Flexibility is an important physiological component of physical fitness and reduced flexibility can cause inefficiency in the workplace and is also a risk factor for low back pain (Odunaiya et al., 2005). Increasing hamstring flexibility was reported to be an effective method for increasing hamstring muscle performance on selective isokinetic conditions (Worrell et al., 1994). Muscle tightness is a limiting factor for optimal physical performance and an important intrinsic factor for sports injury (Odunaiya et al., 2005). They also added that muscle tightness can be reduced by doing some stretching, such as static stretching exercise.

Static stretching has been reported as a therapeutic tool in preventing injuries associated with lack of flexibility as well as in treatment of sports injuries (Hamzat, Adeniyi, Awolola, \& Olaleye, 2004). Many authors have studied different approaches of muscle stretching and the duration of application of such procedures (Worrell et al., 1994; Bandy \& Irion, 1994; Spernoga, Uhl, Arnold, \& Gansneder, 2001), however none of them mentioned on what would be the most effective duration of application.

Some experts specify that flexibility requires range of motion without discomfort or pain. Flexibility is specific to each joint of the body, thus there is no general measurement of flexibility, as there is for cardiovascular fitness. Flexibility is typically measured in the lab using measurement devices, such as a goniometer, flexometer and in the field with tests, such as the sit and reach and the zipper.

It has been suggested theoretically that the associated benefits of flexibility include range of motion and function, improved athletic performance, reduced injury risk, prevention or reduction of post exercise soreness, and improved coordination. Poor flexibility in the hamstring and low back is related to problems in executing and sustaining motor activities in daily life (Bergstrom et al., 1985; Myers \& Huddy, 1985), and with chronic musculoskeletal injuries and back problems, postural deviations, gait limitations, and risk of falling in adults (ACSM, 1998b; Skinner \& Oja, 1994; Witvrouw, Bellemans, Lysens, Danneels, \& Cambier, 2001; Witvrouw et al., 2000).

Besides that, it has been reported that a lack of hip flexibility in young people is associated with a higher risk of low back pain later in life (Kujala, Salminen, Taimela, Oksanen, \& Jaakkola, 1992), and hamstring flexibility (measured by the sit-and-reach test) is one of the best explanatory factors for adult health-related fitness for men (Mikkelsson et al., 2006).

\section{Dance Education in Early Childhood}

Children may attain basic motor skills development through different types of physical activities or educational programs which are given to them, such as dancing or music and movement. Any physical education program for young children shall be accompanied by music and rhythms. It attracts and amuses children more rather than giving children some common and basic physical activities. Kenney (1997) said that rhythms for locomotor skills are carried in the music itself. These locomotor skills include walking, hopping, running, and hoping. Children can express all of these skills in music and sound.

A music and movement program based on movement concepts (body awareness, space awareness, effort concepts, and relationship concepts), on elements of rhythm, and on improvised motor responses, and provides variety to the physical education program (Pica, 2000).

Song games also explore small motor coordination, body parts, movement with partners, and movement in free space (Kenney, 1997). According to Gallahue and Ozmun (1998), some activities in the form of games and rhythmic activities are suitable for pre-schoolers, because these activities prompt children to move, develop body and space awareness, and help them to progress through initial, elementary, and mature stages of acquiring basic skills. 
In his study, Moore (1984) found out that the group who received 10 weeks of rhythmic training has scored significantly higher than the control group during the post-test. In another study, High (1987) found that a rhythmic movement program for a duration of 14 weeks is able to improve pre-schoolers' rhythmic ability more than a program of free-play activities. Therefore, children are attracted more to rhythms and gain learning through rhythms. Music and movement or dance can be one of the best platforms for children to enjoy and learn efficiently.

Movement and dance in preschools provide a variety of experiences, so that children may receive the benefits from creative and complex movement experiences. Movement and music experiences joined within a preschool curriculum can also strengthen math and logic concepts through rhythm and patterns of beat and tempo (Shilling, 2002). Graham (2002) added that creative movement and dance can be a transformative experience that develops body awareness as well as personal identity and control.

For Koff (2000), movement is a form of experience and communication. Movements through dance include emotional expression, counting, rhythm, language, body awareness, and creative body movements. Children learn the movements at levels and rates which are suitable to their interests and abilities.

In dance, there are three phases which are important. The three phases are warming-ups, dance techniques, and creative movement. Warming-up is a preparation for the body before involving in physical activities. Dance techniques refer to body control, whereas creative movement is modifying movement through imagination. Warming-up before doing physical activities helps to understand more the significance of stretching towards muscles.

A preschool movement through dance is able to let children experience an integrated developmental experience of sensory, motor, cognitive, emotional, and also social. Duff, Shumway-Cook, and Woollacott (2007) strongly believed that movement through dance will definitely help in motor skills. An enjoyable and goal-directed task will help more in motor skills rather than doing the movement only. Some dance movements will challenge the children through repetitive movements and different warming-up exercises which will result in a greater outcome of body awareness, sequencing of motor and balancing (Lorenzo-Lasa, R. I. Ideishi, \& S. K. Ideishi, 2007). By using a variety of modes for motor learning, children's problem solving and generalization for effective movement strategies are improved (Duff et al., 2007). The examples of the learning modes are the warming-ups, animal movement, and games facilitate.

Teacher training, physical space, and community integration also need to be considered in planning music and movement or dance program. Teachers may cooperate with experts, such as dance, physical and occupational therapists in order to help in extending the purpose, objectives, and sequence of movement techniques into curricular and therapeutic planning (Lorenzo-Lasa et al., 2007).

\section{Literature Review}

Derri, Tsapakidou, Zachopoulou, and Kioumourtzoglou (2001) carried out a study about "Effect of a Music and Movement Programme on Development of Locomotor Skills by Children 4 to 6 Years of Age". The purpose of their study was to investigate the effect of a 10 -week music and movement programme on the quality of locomotor skills in children 4 to 6 years of age. The subjects involved in this study were 68 children (33 girls and 35 boys). The children were divided into two groups and only one group (experimental group) will be participating in an exercise programme. The exercise programme was carried out twice a week and they were assessed by using the Test of Gross Motor Development. The result showed that the experimental group 
had a great improvement on the locomotor skills (running, skipping, galloping, hopping, leaping, sliding, and horizontal jump) as compared to the controlled group. It seemed that a music and movement programme can improve significantly the quality of certain, more complex locomotor skills (Derri et al., 2001).

Derri, Tsapakidou, Zachopoulou, and Kioumourtzoglou (2004) carried out a study about "The Effects of a Developmentally Appropriate Music and Movement Program on Motor Performance". The purpose of their study was to investigate and compare the effects of a developmentally appropriate music and movement program and of developmentally appropriate physical education program on the development of jumping and dynamic balance in children aged four to six years. The subjects involved in this study were 90 children who consist of 48 boys and 42 girls. The experimental group was participating in the music and movement program, whereas the controlled group participated in physical educational program. Both groups' participation lasted for two months. The result showed that the experimental group performs better in the jumping and dynamic balance as compared to the controlled group. They concluded that there was a positive effect on the jumping and dynamic balance of preschool children through a developmentally appropriate music and movement program.

Lorenzo-Lasa et al. (2007) also carried out a study about "Facilitating Preschool Learning and Movement through Dance". The purpose of their study was to suggest different types of warm up exercises (floor and seated exercises, standing exercises), ballet techniques, and animal movements for children. They strongly believed that a preschool movement through dance program is a way to open the door to numerous benefits and opportunities. Movement through dance could facilitate children's meaning, expression, and intention (Lorenzo-Lasa et al., 2007).

Odunaiya et al. (2005) carried out a study about "The Effects of Static Stretch Duration on the Flexibility of Hamstring Muscles". There were six samples in their study which were randomly given one of five intervention and one controlled group. They were required to stretch their hamstring passively for 120, 90, 60, 30, and 15 seconds each person, according to the intervention given. The intervention program took six weeks, carried out on alternate days. The result showed that stretching of hamstring for duration of 15 seconds up to 120 seconds for six weeks on alternate days can improve flexibility. They also found out that this positive effect was maintained for seven days after the intervention ends.

Castro-Piñero et al. (2013) carried out a study about "Percentile Values for Flexibility Tests in Youths Aged 6 to 17 Years: Influence of Weight Status". The purpose of their study was to examine the influence of weight status on flexibility performance. With a total of 1,712 subjects (1,237 girls and 1,475 boys), they categorised them as underweight, normal weight, overweight, and obese. The results showed that there was a significant relationship between weight and flexibility. Besides that, gender and age were also factors which influence flexibility in this study.

Although there are plenty of studies on flexibility and dance which show significant changes towards flexibility through intervention programs, there are also studies in which its results are showing different result, for example, a study carried out by Hamidi (2007) which investigated the effectiveness of regular physical education towards health-related physical fitness and evaluated the effectiveness of an intervention program on health-related physical fitness among primary school children (Hamidi, 2007). The result of the flexibility component showed insignificant changes after undergoing an intervention program for eight weeks. Sinappan's study (2006) also showed an insignificant result in the improvement of flexibility.

There are not many studies related to the flexibility in pre-schoolers and dance is usually related to social and emotional development rather than physical development. Therefore, researcher considered to carry out 
dance sessions as the intervention program for this study and examine whether there is a significant change in the flexibility of pre-schoolers.

\section{Research Design}

To achieve the purpose of this study, researcher used the method of quasi experimental which included pre- and post-test in order to compare two subjects from two different groups which are the controlled group and experimental group. This method was chosen due to inability to group the children randomly.

There are three classes of six years old children in this kindergarten. The boys from these three classes were all involved in this research. Each of them was selected to be the research samples. Fifteen boys $(N=15)$ were chosen randomly by the kindergarten principal to be in the controlled group and the other 15 boys $(N=15)$ were put into the experimental group.

This study was carried out for 10 weeks. During the first week, a pre-test was carried out onto both controlled and experimental group to collect data regarding their flexibility. The controlled group was given table top activities for the entire eight weeks, however, the experimental group participated in a 45-minute dance session which was carried out once a week for the entire eight weeks. The dance sessions consist of warming-up session, music and movement, dance, and cooling down session. During the 10th week, a post-test was carried out onto both groups (controlled group and experimental group) for data collection regarding their flexibility. The post-test data collected were used to make comparison between pre- and post-test results which then were used to evaluate the effectiveness of the 45-minute dance session in enhancing the flexibility of six years old boys. Figure 1 below shows the process of selecting the subjects for this study.

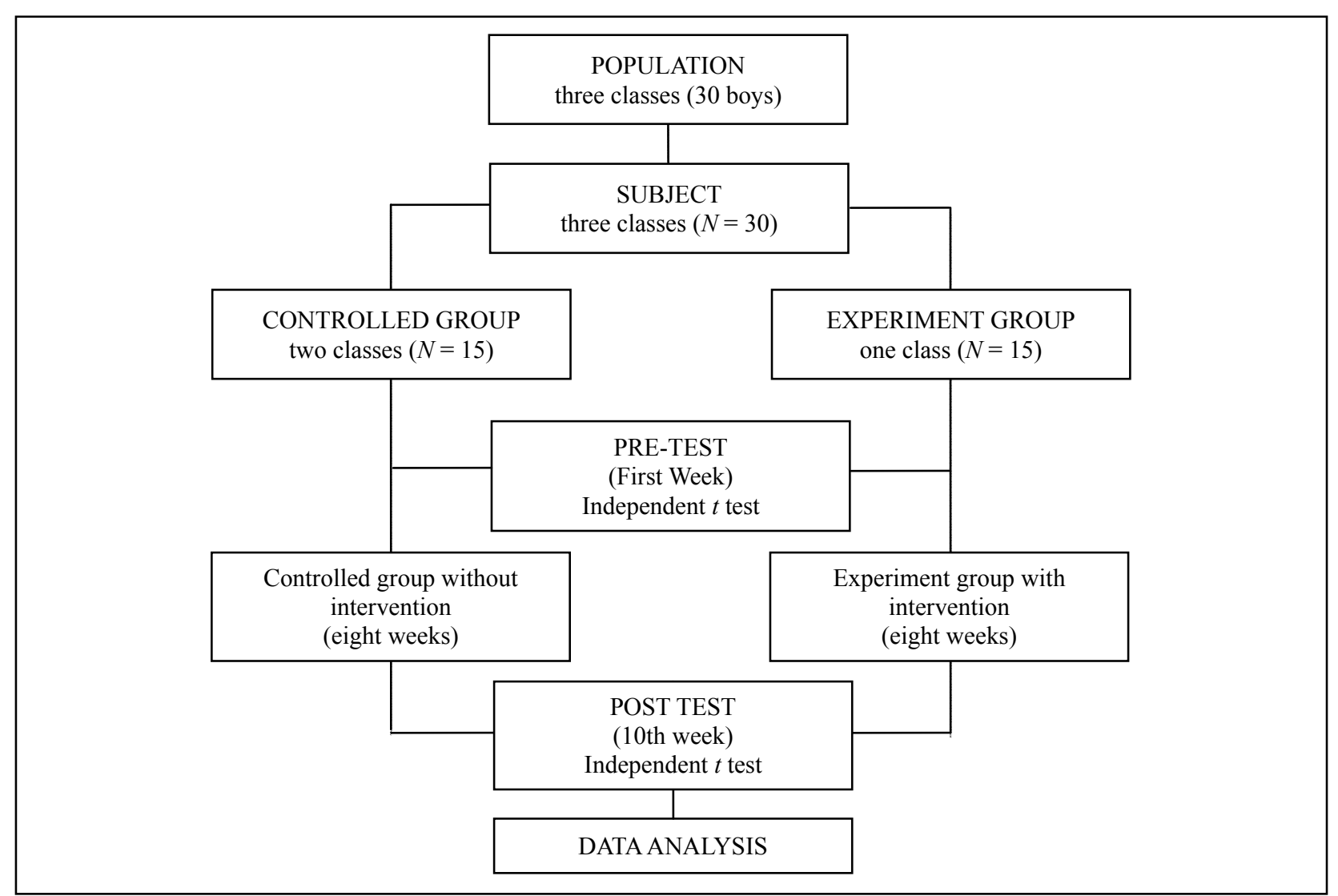

Figure 1. Process of selecting the subjects. 


\section{Instrument}

Components of physical fitness include cardiovascular endurance, muscle strength, muscle endurance, flexibility, and body composition. However, this study is examining the enhancement of physical fitness in the aspect of flexibility only. To measure the flexibility aspect, researcher used V-sit and reach test.

$\mathrm{V}$-sit and reach test-Flexibility. V-sit and reach test is a variation test of the sit and reach which was first described by Wells and Dillon in 1952 and nowadays it is used generally by most people to test flexibility. Sit-and-reach test is commonly used in health fitness test batteries to estimate hamstring flexibility (Australian Council for Health, Physical Education and Recreation, 1996; Behm, Faiqenbaum, Falk, \& Klentrou, 2008; Council of Europe Committee for the Development of Sport, 1993) and several modified version of it such as $\mathrm{V}$-sit and reach has been developed to increase the accuracy and provide a safer procedures (Castro-Piñero et al., 2013). V-sit and reach test is similar to sit and reach test. The difference is instead of using a box, V-sit and reach test used lines on the ground. It is widely used because of its simple and easy procedures. This test aimed to measure the flexibility of the hamstring and the lower back muscles. Before carrying out the test, parents of each child were given an explanation of the purpose of the study. A consent letter was also given to be filled by the parents before the test.

\section{Research Findings}

\section{Descriptive Statistic of Pre- and Post-test for Controlled Group and Experimental Group Related to Flexibility}

Table 1 below shows the finding of descriptive statistic about the mean scores for pre- and post-test for controlled and experimental group related to flexibility.

The mean score of pre-test for controlled group related to flexibility component is 2.67 and the standard deviation (SD) is 0.82 , whereas the mean score of the post-test is 2.87 with its standard deviation (SD) of 1.19. The mean score of post-test for experimental group is 2.87 and the standard deviation (SD) is 0.92 , whereas the mean score for the post-test is 3.40 with its standard deviation (SD) of 1.18.

Table 1

Descriptive Statistic of Pre- and Post-test for Controlled Group and Experimental Group

\begin{tabular}{llllll}
\hline Component & & \multicolumn{3}{c}{ Controlled group } & Experimental group \\
\hline \multirow{5}{*}{ Flexibility } & & Pre-test & Post-test & Pre-test & Post-test \\
\cline { 2 - 6 } & Mean & 2.67 & 2.87 & 2.87 & 3.40 \\
& SD & 0.82 & 1.19 & 0.92 & 1.18 \\
& Max. & 4.00 & 5.00 & 4.00 & 5.00 \\
& Min. & 1.00 & 1.00 & 1.00 & 1.00 \\
\hline
\end{tabular}

Analysis of Independent $\boldsymbol{T}$-test Unto the Pre-test Score Between the Controlled Group and the Experimental Group Related to Flexibility

Table 2 shows the comparison of pre-test score between the controlled group and the experimental group. From this finding, it can be seen that the mean score for controlled group is 2.67 with its standard deviation (SD) of 0.82 , whereas the mean score for experimental group is 2.87 with its standard deviation (SD) of 0.92 . The difference of the mean is 0.20 . Independent $t$-test for both groups shows the value of $t=0.63$, with significance of 0.53 which is not significant $(p>0.05)$. This result shows no significant difference 
related to flexibility between controlled and experimental group. This finding also shows that both groups are equal.

Table 2

The Comparison of Pre-test Between the Controlled Group and the Experimental Group Related to Flexibility

\begin{tabular}{|c|c|c|c|c|c|c|c|}
\hline & Group & Mean & Mean difference & $\mathrm{SD}$ & $F$ & $t$-value & Significance \\
\hline \multirow{2}{*}{ Pre-test } & Controlled & 2.67 & \multirow{2}{*}{0.20} & 0.82 & \multirow{2}{*}{0.06} & \multirow{2}{*}{0.63} & \multirow{2}{*}{0.53} \\
\hline & Experimental & 2.87 & & 0.92 & & & \\
\hline
\end{tabular}

\section{Analysis of Paired T-test Within the Controlled Group Related to Flexibility}

Table 3 shows the comparison of the mean score for pre- and post-test within the controlled group. This finding shows that mean score for pre-test is 2.67 with its standard deviation (SD) of 0.82, whereas the mean score for post-test is 2.87 with its standard deviation (SD) of 1.19 . The mean difference is 0.20 . Paired $t$-test for both pre- and post-test shows the value of $t=-1.15$, with significance of 0.27 which is not significant $(p>0.05)$ In this study, there is no significant difference between pre- and post-test towards the flexibility of the controlled group.

Table 3

Comparison Between the Scores of Pre- and Post-test Within the Controlled Group

\begin{tabular}{llllll}
\hline Controlled group & Mean & Mean difference & SD & $t$-value & Significance \\
\hline Pre-test & 2.67 & 0.20 & 0.82 & -1.15 & 0.27 \\
Post-test & 2.87 & 1.19 & & \\
\hline
\end{tabular}

\section{Analysis of Paired $\boldsymbol{T}$-test Within the Experimental Group Related to Flexibility}

Table 4 shows that mean score for pre-test for the experimental group is 2.87 with its standard deviation (SD) of 0.92 , whereas the mean score for post-test is 3.40 with its standard deviation (SD) of 1.18. The mean difference is 0.53 . Paired $t$-test for both pre- and post-test shows the value of $t=-2.26$, with significance of 0.04 which is significant $(p<0.05)$. In this study, there is a significant difference between pre- and post-test towards the flexibility of the experimental group.

Table 4

Comparison Between the Scores of Pre- and Post-test Within the Experimental Group

\begin{tabular}{llllll}
\hline Experimental group & Mean & Mean difference & SD & $t$-value & Significance \\
\hline Pre-test & 2.87 & 0.53 & 0.92 & -2.26 & 0.04 \\
Post-test & 3.40 & & 1.18 & & \\
\hline
\end{tabular}

\section{Independent $\boldsymbol{T}$-test for the Post-test Between Controlled Group and Experimental Group Related to Flexibility}

Table 5 shows the mean score for the post-test between controlled group and experimental group. Mean score for the post-test of controlled group is 2.87 with its standard deviation (SD) of 1.19 , whereas mean score for the post-test of experimental group is 3.40 with its standard deviation (SD) of 1.18. The difference of mean is 0.53 . Independent $t$-test for both tests shows the value of $t=1.23$ with significance of 0.23 , which is not significant $(p>0.05)$. This result shows that there is no significant difference between the post-test of controlled group and experimental group related to flexibility. 
Table 5

Comparison of Post-test Score Between Controlled Group and Experimental Group Related to the Flexibility

\begin{tabular}{llllllll}
\hline & Group & Mean & Mean difference & SD & $F$ & $t$-value & Significance \\
\hline \multirow{2}{*}{ Post-test } & Controlled & 2.87 & \multirow{2}{*}{0.53} & 1.19 & \multirow{2}{*}{0.02} & \multirow{2}{*}{1.23} & \multirow{2}{*}{0.23} \\
& Experimental & 3.40 & & 1.18 & & \\
\hline
\end{tabular}

\section{Discussion}

\section{Research Question One}

Is there any significant difference in the enhancement of flexibility between the mean score of pre- and post-test within the controlled group?

The controlled group does not participate in the 45-minute dance sessions, but they do the table top activities prepared by researcher. The table top activities consist of colouring, matching alphabet, number sequence, and origami.

The result of the study shows that there is no significant difference in the flexibility between the pre- and post-test of the controlled group. According to Table 3, the mean scores of pre- and post-test for controlled group are very close to each other. Through paired $t$-test, the result indicates an insignificant difference. Therefore, controlled group who does not participate in the intervention program shows an insignificant difference in their flexibility.

The children in controlled group who do not participate in the 45-minute dance sessions do not show a significant difference in their flexibility. This is because they do not receive any stressor which causes the enhancement in flexibility. They are all sitting on their chair while doing the table top activities. There are no dance activities or other physical activities carried out with this group.

This result proves that there will be no enhancement in flexibility if children are not involved in stretching, dance or other physical activities. In daily life, children love to play computer games (Dorman, 1997) or iPad or watching TV shows rather than having sports or physical activities. Their flexibility and physical fitness will drop if this remains for a long period of time. Therefore, parents, educators, and the society have to put this into concern, so that the physical fitness among children will not continue to drop. Hence, it can be concluded that there is no significant difference in the flexibility of pre-schoolers, if they are not participating in the intervention program.

\section{Research Question Two}

Is there any significant difference in the enhancement of flexibility between the mean score of pre- and post-test within the experimental group?

The experimental group participates in the 45 -minute dance sessions with once a week frequency. The result shows that the flexibility in the children of experimental group experiences a significant difference after undergoing the intervention program for eight weeks continuously.

According to Table 4, the mean score of post-test for experimental group is higher than the mean score of pre-test. The mean difference between the pre- and post-test is 0.53 . Through paired $t$-test within the experimental group, the result indicates a significant difference. Therefore, experimental group who participates in the intervention program shows a significant difference in their flexibility.

The children in experimental group who participate in the 45-minute dance sessions show a significant difference in their flexibility. This is because they receive stressor which causes the enhancement in flexibility. 
The dance session consists of warming-ups, stretching, and movements which are helpful for the children's flexibility. As specified by ACSM (1998b), stretching exercise helps in developing flexibility.

The result of this study is similar to the studies carried out by Derri et al. (2004), Jackson, Morrow, Hill, and Dishman (1999), Jackson and Langford (1989) which prove that an intervention program in the form of stretching activities is beneficial in improving flexibility. The intervention is carried out with the frequency of two to three times a week.

The intervention given to the children in this present study has given enough stress to the muscles which creates physiological adaptation process during the dance, as what is suggested by Wilmore (1997), Ignico and Mahon (1995). According to the General Adaptation Syndrome (GAS) theory, the changes in the physiological adaptation lessen the reaction towards the stressor, which increase the flexibility of the children in experimental group.

A regular structured intervention program is able to enhance children's flexibility. In kindergartens, educators shall use the music and movement lessons as an intervention to improve children's physical fitness. It can be concluded that 45 -minute dance session is an effective intervention program for pre-schoolers to enhance their flexibility.

\section{Research Question Three}

Is there any significant difference between the mean score of pre- and post-test in the enhancement of flexibility between the controlled group and the experimental group?

All of the subjects from controlled group and experimental group have taken the pre-test on the first week of this study. The children in controlled group and experimental group have participated in the table top activities and the dance sessions respectively. A post-test is carried out on the 10th week, to determine the significant difference between these two groups.

The result of the study shows that there is no significant difference in the flexibility between controlled group and experimental group. According to Table 5, although the mean score of post-test for controlled group is still lower than the mean score of post-test for experimental group, independent $t$-test between both groups indicates an insignificant difference. Therefore, experimental group who underwent the 45-minute dance sessions once a week for eight weeks continuously does not show a significant difference in their flexibility as compared to the controlled group.

The children in experimental group who participated in the 45-minute dance sessions do not show a significant difference in their flexibility. This is because physiology adaptation does not occur much during the intervention process. As mentioned in the GAS theory, physiological adaptation will only occur through stressors which are given to the body and results in a positive achievement. In this study, the stressor given is too little than the exact amount of stressor that should be given. The stressor can be increased by increasing the frequency of dance sessions. In their studies, Wilmore (1997) and Shephard (1999) mentioned that a progressive overload, duration of training, the frequency of training, intensity of training and the ratio of work and rest are the factors which have to be paid attention to so that adaptation will occur and show a positive effect in one's body. Therefore, the frequency of dance sessions can be increased from once a week to three times a week on alternative days.

Some other factors which may influence this finding are the attendance of the children in the experimental group (decreasing mean score) and the active lifestyle of the children in the controlled group (increasing mean 
score). There are two children who only attend the dance sessions twice out of eight sessions. They are not fully participated in this intervention program. Some children in the controlled group may have an active lifestyle. Therefore, their flexibility may be good, although they are not undergoing the dance sessions. Their flexibility may increase unconsciously through their daily active lifestyle. These are some limitations in this study which influence the finding.

The result of this study is similar to a study carried out by Hamidi (2007). The intervention is carried out twice a week for eight weeks. In his study, the flexibility of the experimental group does not show a significant difference as compared to the controlled group. Another study carried out by Sinappan (2006) also shows an insignificant difference in the flexibility of the subjects. In his study, the intervention program is carried out once a week which is the same frequency as this present study. However, it is strongly believed that intervention program brings positive effects to the flexibility, if the frequency is increased because there are studies which show significant result in enhancing flexibility through intervention program.

According to ACSM, to maintain physical fitness, three to five days are needed to do exercises. Hence, dance session with once a week frequency is not enough to enhance pre-schoolers' flexibility. Study of Odunaiya et al. (2005) results in a significant improvement in flexibility through intervention with three times a week on alternative days. At such, it can be concluded that this 45-minute dance session still can be considered as an intervention program with a modification on the frequency as suggested by researcher later on.

\section{Conclusions}

The purpose of this research is to examine to what extent the effectiveness of dance will be in enhancing pre-schoolers' flexibility through a dance session of 45 minutes per week. These dance sessions are carried out once a week for eight weeks continuously among the boys aged six years old in a kindergarten in Penang. The intervention program which is given to the children in the experimental group shows an insignificant change. However, the experimental group is showing a significant improvement in flexibility as compared to the children in the controlled group.

Flexibility is one of the important components in the health-related physical fitness. Children's failure in enhancing and maintaining flexibility today will lead to more severe problems in the future, such as easily injured, muscles soreness, lower back pain, postural deviations, and gait limitations. To develop the awareness of the importance of flexibility, educators have to plan suitable activities which are beneficial towards the children's flexibility. Music and movement can be used as a platform to help in enhancing their flexibility.

It can be concluded that when an intervention program is carried out with an appropriate principal by using suggestions in the GAS theory systematically, it will result in positive effects. In this study, the frequency of the dance sessions (intervention) has to be increased as suggested in GAS theory in order to achieve a significant result in the flexibility of the pre-schoolers.

\section{References}

American Alliance for Health, Physical Education, Recreation \& Dancer. (1980). AAHPERD lifetime health related physical fitness: Test manual. Reston.

American College of Sports Medicine. (1998a). ACSM fitness book (2nd ed.). Champaign: Illinois Human Kinetic.

American College of Sports Medicine. (1998b). Position stand. Exercise and physical activity for older adults. Medicine \& Science in Sports \& Exercise, 30, 992-1008. 
Australian Council for Health, Physical Education and Recreation. (1996). Handbook for the Australian fitness education award manual. Melbourne: ACHPER Victorian Branch.

Bandy, W. D., \& Irion, J. M. (1994). The effects of time of static stretch on the flexibility of the hamstring muscles. Physical Therapy, 74, 845-856.

Behm, D. G., Faiqenbaum, A. D., Falk, B., \& Klentrou, P. (2008). Canadian society for exercise physiology position paper: Resistance training in children and adolescents. Appl Physio Nutr Metabb, 33(3), 547-561.

Bergstrom, G., Aniansson, A., Bjelle, A., Grimby, G., Lundgren-Lindquist, B., \& Svanborg, A. (1985). Functional consequences of joint impairment at age 79. Scandinavian Journal of Rehabilitation Medicine, 17, 183-190.

Castro-Piñero, J., Girela-Rejón, M. J., González-Montesinos, J. L., Mora, J., Conde-Caveda, J., Sjöstöm, M., \& Ruiz, J. R. (2013). Percentile values for flexibility tests in youths aged 6 to 17 years: Influence of weight status. European Journal of Sport Science, 13(2), 129-148.

Corbin, C. B., \& Noble, L. (1980). Flexibility: A major component of physical fitness. Journal of Physical Education and Recreation, 51(6), 23-26.

Council of Europe Committee for the Development of Sport. (1993). EUROFIT: Handbook for the EUROFIT tests of physical fitness. Strasbourg: Council of Europe.

Derri, V., Tsapakidou, A., Zachopoulou, E., \& Kioumourtzoglou, E. (2001). Effect of a music and movement programme on development of locomotor skills by children 4 to 6 years of age. European Journal of Physical Education, 6(1), 16-25.

Derri, V., Tsapakidou, A., Zachopoulou, E., \& Kioumourtzoglou, E. (2004). The effects of a developmentally appropriate music and movement program on motor performance. Early Childhood Research Quarterly, 19(1), 631-642.

Dorman, S. M. (1997). Video and computer games: Effect on children and implications for health education. Journal of School Health, 67(4), 133-138.

Duff, S., Shumway-Cook, A., \& Woollacott, M. H. (2007). Clinical management of the patient with reach, grasp and manipulation disorders. In A. M. H. Shumway-Cook Woollacott (Ed.), Motor control: Translating research into clinical practice (pp. 548-554). Philadelphia: Lippincott, Williams \& Wilkins.

Fisk, J. (2013).Child's flexibility issues. Retrieved from http://www.livestrong.com/article/351922-childs-flexibility-issues/

Gallahue, D., \& Ozmun, J. (1998). Understanding motor development. Infants, children, adolescents, adults. New York: McGraw-Hill.

Graham, S. F. (2002). Dance: A transformative occupation. Journal of Occupational Science, 9, 128-134.

Hamidi, M. A. (2007). Effectiveness of an intervention programme on physical fitness components among primary school children (Master's Thesis, Faculty of Education, University of Malaya, Kuala Lumpur).

Hamzat, T. K., Adeniyi, A. F., Awolola, O. E., \& Olaleye, O. A. (2004). Injury pattern of FIFA, CAF and UEFA soccer tournaments: A retrospective study of selected 2002 matches. South African Journal of Physiotherapy, 60(3), 10-14.

High, L. (1987). Effects of selected rhythmic teaching strategies on beat performance skills of kindergarten children. Dissertation Abstracts International, 48, 3067.

Ignico, A. A., \& Mahon, A. D. (1995). The effects of a physical fitness program on low fit children. Research Quarterly for Exercise and Sports, 66(1), 85-90.

Jackson, A. W., \& Langford, N. J. (1998). A criterion related validity of the sit and reach test. Replication and extension of previous findings. Research Quarterly for Exercise and Sports, 60(4), 384-387.

Jackson, A. W., Morrow, J. R., Hill, D. W., \& Dishman, R. K. (1999). Physical activity for health and fitness: An individualized lifetime approach. Hong Kong: Human Kinetics.

Kenney, S. (1997). Music in the developmentally appropriate integrated curriculum. In C. Hart, D. Burts, and R. Charlesworth (Eds.), Integrated curriculum and developmentally appropriate practice: Birth to age eight (pp. 103-144). Albany: SUNY Press.

Koff, S. (2000). Toward a definition of dance education. Childhood Education, 77(1), 27-31.

Kujala, U. M., Salminen, J. J., Taimela, S., Oksanen, A., \& Jaakkola, L. (1992). Subject characteristics and low back pain in young athletes and nonathletes. Medicine \& Science in Sports \& Exercise, 24, 627-632.

Lake, R. (2013). The benefits of dance for kids. Retrieved from http://www.livestrong.com/article/ 214791-the-benefits-of-dance-for-kids/

Lorenzo-Lasa, R., Ideishi, R. I., \& Ideishi, S. K. (2007). Facilitating preschool learning and movement through dance. Early Childhood Education Journal, 35(1), 25-31.

Medeiros, J. M., Smidt, G. L., Burmeiser, L. F., \& Soderberg, G. L. (1977). The influence of isometric exercise and passive stretch on hip joint motion. Physical Therapy, 57, 518-522. 
Mikkelsson, L., Kaprio, J., Kautiainen, H., Kujala, U., Mikkelsson, M., \& Nupponen, H. (2006). School fitness tests as predictors of adult health-related fitness. American Journal of Human Biology, 18, 342-349.

Moore, J. (1984). Rhythm and movement: An objective analysis of their association with music aptitude. Dissertation Abstracts International, 45, 1328A.

Müller A. M., Khoo, S., \& Lambert, R. (2013). Review of physical activity prevalence of Asian school-age children and adolescents. Asia-Pacific Journal of Public Health, 25(3), 227-238.

Myers, A. M., \& Huddy, I. (1985). Evaluating physical capabilities in the elderly: The relationship between ADL self-assessments and basic abilities. Canadian Journal of Aging, 4, 189-200.

Odunaiya, N. A., Hamzat, T. K., \& Ajayi, O. F. (2005). The effects of static stretch duration on the flexibility of hamstring muscles. African Journal of Biomedical Research, 8, 79-82.

Pica, R. (2000). Experiences in movement with music, activities, and theory. Delmar: Thomson Learning.

Rengasamy, S. (1998). Health related fitness: Curriculum outlook and implementation problems. Masalah Pendidikan, 21, 23-33.

Salamudin, N., \& Harun, M. T. (2013). Physical activity index among Malaysian youth. Asian Social Science, 9(12), 99-104.

Sell, S. (2004). Preschool dance. Journal of Dance Education, 4(4), 119-120.

Shephard, R. J. (1999). How much physical activity is needed for good health? International Journal of Sports Medicine, 20 , 23-27.

Shilling, W. A. (2002). Mathematics, music, and movement: Exploring concepts and connections. Early Childhood Education Journal, 29, 179-184.

Sinappan, R. (2006). Effectiveness of an intervention programme on physical fitness among primary school children (Master's Thesis, Faculty of Education, University of Malaya, Kuala Lumpur).

Skinner, J. S., \& Oja, P. (1994). Laboratory and field tests for assessing health-related fitness. In C. Bouchard, R. J. Shephard, and T. Stephens (Eds.), Physical activity, fitness and health (pp. 160-179). Champaign: Human Kinetics.

Spernoga, S. G., Uhl, T. H., Arnold, B. L., \& Gansneder, B. M. (2001). Duration of maintained hamstrings flexibility after a one time, modified hold relax stretching protocol. Journal of Athletic Training, 36(1), 44-46.

Strickland, D. (2006). Dance provides youth with mind and body benefits. Family Talk Magazine. Retrieved from http://www.wellspringdance.org/assets/docs/family_talk_article_06.pdf

Turner, D., Gossman, R. M., Nicholson, C. G., \& Lemons, J. (1988). Comparison of cyclic and sustained passive stretching using a mechanical device to increase resting length of hamstring muscles. Physical Therapy, 69(3), 314-320.

Wells, K. F., \& Dillon, E. K. (1952). The sit and reach: A test of back and leg flexibility. Research Quarterly for Exercise and Sport, 23, 115-118.

Wilmore, J. H. (1997). Athletic training and physical fitness: Physiological principles and practices of the conditioning process. Boston: Allyn Bacon, Inc.

Witvrouw, E., Bellemans, J., Lysens, R., Danneels, L., \& Cambier, D. (2001). Intrinsic risk factors for the development of patellar tendinitis in an athletic population. A two-year prospective study. American Journal of Sports Medicine, 29, 190-195.

Witvrouw, E., Lysens, R., Bellemans, J., Cambier, D., \& Vanderstraeten, G. (2000). Intrinsic risk factors for the development of anterior knee pain in an athletic population. A two-year prospective study. American Journal of Sports Medicine, 28, 480-489.

Worrell, T. W., Smith, T. L., \& Winegardner, J. (1994). Effect of hamstring stretching on hamstring muscle performance. Journal of Orthopaedic and Sports Physical Therapy, 20(3), 154-159. 